\title{
Factors affecting time to sputum culture conversion and treatment outcome of patients with multidrug-resistant tuberculosis in China
}

\author{
Qiao Liu ${ }^{1 \dagger}$, Peng Lü ${ }^{2 \dagger}$, Leonardo Martinez ${ }^{3+}$, Haitao Yang ${ }^{2,4}$, Wei Lu ${ }^{1}$ Xiaoyan Ding ${ }^{1}$ and Limei Zhu ${ }^{1 *}$
}

\begin{abstract}
Background: Few prospective cohort studies, none in China, have investigated the relationship between treatment outcomes of multidrug-resistant tuberculosis (MDR-TB) patients and sputum culture conversion. Factors affecting the time of the culture conversion throughout the whole course of the treatment have rarely been investigated.

Methods: This study was performed in four cities in Jiangsu province, China. MDR-TB patients were consecutively enrolled between December 2011 and March 2014. Rates of sputum culture conversion were calculated and Cox proportional-hazards model was performed. Factors contributing to sputum culture conversion were investigated.

Results: In all, 139 MDR-TB patients with treatment outcomes were enrolled. Median time to culture conversion among those who converted was 91.5 days (interquartile range, 34.0-110.8 days). After multivariable analysis, smoking $(H R=0.44 ; 95 \% \mathrm{Cl}: 0.23-0.83)$, drinking ( $H R=0.41 ; 95 \% \mathrm{Cl}: 0.21-0.81)$, ofloxacin resistance ( $H R=0.43 ; 95 \% \mathrm{Cl}: 0.24-0.76)$ and sputum smear grade $>1(\mathrm{HR}=0.51 ; 95 \% \mathrm{Cl}: 0.31-0.83)$ were less likely to have culture conversion.

Conclusions: MDR-TB patients who smoke, drink, have ofloxacin resistance, or a high smear grade are less likely to respond to treatment and should be meticulously followed up.
\end{abstract}

Keywords: Multidrug-resistant tuberculosis, Risk factors, Sputum culture conversion, Treatment outcome

\section{Background}

Tuberculosis (TB) now exceeds human immunodeficiency virus (HIV) as the infectious disease responsible for the greatest number of deaths globally [1]. In addition, multidrug-resistant tuberculosis (MDR-TB), patients resistant to rifampicin (INH) and isoniazid (RMP), hampers the prevention and control of tuberculosis. Due to poor effectiveness and elevated costs in treatment of MDR-TB patients, they may endure longer infectious periods than those with drug-susceptible TB [2]. Early identification and diagnosis of MDR-TB patients are essential to further prevent the spread of MDR-TB and provide comprehensive and successful treatment.

\footnotetext{
* Correspondence: jsjkmck@163.com

${ }^{\dagger}$ Equal contributors

'Department of Chronic Communicable Disease, Center for Disease Control and Prevention of Jiangsu Province, Nanjing, Jiangsu Province, People's Republic of China

Full list of author information is available at the end of the article
}

Sputum culture plays an important role in monitoring treatment response in MDR-TB patients [3]. Sputum culture conversion is a clinical tool used to predict therapeutic efficacy in MDR-TB patients. Non-conversion of sputum culture at the end of the intensive phase of treatment tends to yield unfavorable outcomes, more specifically with failure and death $[4,5]$.

Evidence exists suggesting that sputum culture conversion after the first 2 months may be an early predictor of treatment success in MDR-TB patients [6-8]. Lung cavitation at baseline chest X-ray and resistance to ofloxacin (Ofx) or streptomycin have been associated with a delay in sputum culture conversion in prior studies [6]. Although sputum culture conversion has been used substantially in clinical settings, few prospective cohort studies have been performed in China and India, two countries with almost half of the global burden of drug resistant tuberculosis $[9,10]$. In addition, factors affecting 
the time of the culture conversion throughout the whole course of the treatment have rarely been investigated.

Through a prospective cohort study design in urban China, we analyzed secondary factors that influenced sputum culture conversion in the process of treatment of MDR-TB disease.

\section{Methods}

\section{Study design and patients}

A prospective cohort study was conducted in four cities (Xuzhou, Lianyungang, Zhenjiang, and Nantong) in Jiangsu province, China, as previously described [11]. All MDR-TB patients were consecutively enrolled in the study between December 2011 and March 2014. MDR-TB patients were identified at the time of diagnosis by regional reference laboratories using traditional drug sensitivity tests (DST), as previously described [12]. Patients that tested sputum culture negative at baseline were excluded. Once confirmed, every patient signed an informed consent form, after which a questionnaire designed by local investigators was administered to gather important demographic and clinical information. The questionnaire contained characteristics including age, sex, weight, and any history of smoking or drinking. In addition, laboratory examination information was collected including sputum smear, sputum culture, chest radiograph findings, and drug sensitivity test results. Sputum culture results were examined at monthly intervals during the intensive phase and 2-monthly intervals during the continuation phase.

\section{Definitions}

World Health Organization guidelines [13] were consulted when defining individuals and variables in our study. MDRTB patients were defined as those who were resistant to at least INH and RMP for Mycobacterium tuberculosis (MTB) in vitro. A positive sputum culture was defined as a colony for MTB [5] and negative when there was no acid-fast bacillus (AFB) in 300 fields. Sputum culture conversion was defined as two consecutive negative cultures after the first sputum sample, collected at least 30 days apart. Persistent positive sputum culture was defined as no sputum culture conversion during the two years treatment period. Final outcomes included success, failure, and death. Sputum smear grading of TB patients was as follows: 1+ (3-9 AFB in 100 fields), $2+$ (1-9 AFB in 10 fields), $3+$ (1-9 AFB in 1 field) and $4+(\geq 10$ AFB in 1 field). Sputum smear grading was divided into two groups, i.e., $\leq 1$ (includes sputum smear negative and positive $1+$ ) and $>1$ (includes sputum smear positive $2+, 3+$, and $4+$ ).

\section{Regimens}

Directly Observed Treatment was administered by trained nurses during hospitalization or through in-house visits by a physician. The standardized regimen of patients usually contains two phase: the intensive phase and the continuation phase. The total duration of therapeutics for MDRTB patients is 24-27 months, depending on the duration of the intensive phase [14]. Drugs used to treat MDR-TB included pyrazinamide $(\mathrm{Z})$, ethambutol (E), kanamycin $(\mathrm{Km})$, amikacin (Am), capreomycin (Cm), Ofx, levofloxacin (Lfx), moxifloxacin (Mfx), cycloserine (Cs), para-amino salicylic acid (PAS), and protionamide (Pto). All confirmed MDRTB patients were treated with a standardized treatment regimen or an individualized regimen of second line drugs, devised based on a patient's history of TB treatment and DST results.

\section{Statistical analysis}

Statistical analysis was conducted using SPSS software (version 23.0). Cox proportional-hazards analysis was used to evaluate the hazard ratio (HR). Variables were considered suggestive of potential statistical significance if the $P$-value was $<0.05$ in univariate analysis. Multivariable analysis was used to estimate HR and adjusted survival curves. Age and sex were put into the multivariable model regardless of their $P$-value $<0.05$. HRs of the differences between the two groups were calculated to evaluate influential factors affecting time to sputum culture conversion. When the HR was $<1$, the variable was a risk factor.

\section{Results}

\section{Characteristics of enrolled MDR-TB patients}

Between 2011 and 2014, a total of 160 suspected pulmonary MDR-TB patients were recruited of which 21 did not meet study inclusion criteria (Fig. 1). A total of 139 pulmonary MDR-TB patients with a treatment outcome classified as successful, failure, and death were enrolled in our investigation. There were no patients that started the study and then dropped out of the study.

Table 1 displays demographic and clinical characteristics of included MDR-TB patients. The median age and weight of the patients were 51 years old and $60 \mathrm{~kg}$, respectively; 99 (71.4\%) were male; $65(46.8 \%)$ smoked previously or at the time of treatment, and 26 (18.7\%) drank alcohol.

Of 139 MDR-TB patients, 84 (60.4\%) patients had a successful treatment outcome and 55 (39.6\%) experienced either a failed treatment or died. In all, 106 (76.3\%) patients had sputum-culture conversion, of which 18 had a second positive sputum culture during the first year of the treatment. Median time to culture conversion among those who converted was 91.5 days (interquartile range, 34.0110.8 days).

\section{Baseline regimens}

Among 139 patients, 63 (45.3\%) were treated with individualized regimens (IR); 42 (30.2\%) were treated with standard regimen 1 (SR1: 6Z Am Lfx Cs Pto/18Z Lfx Cs 


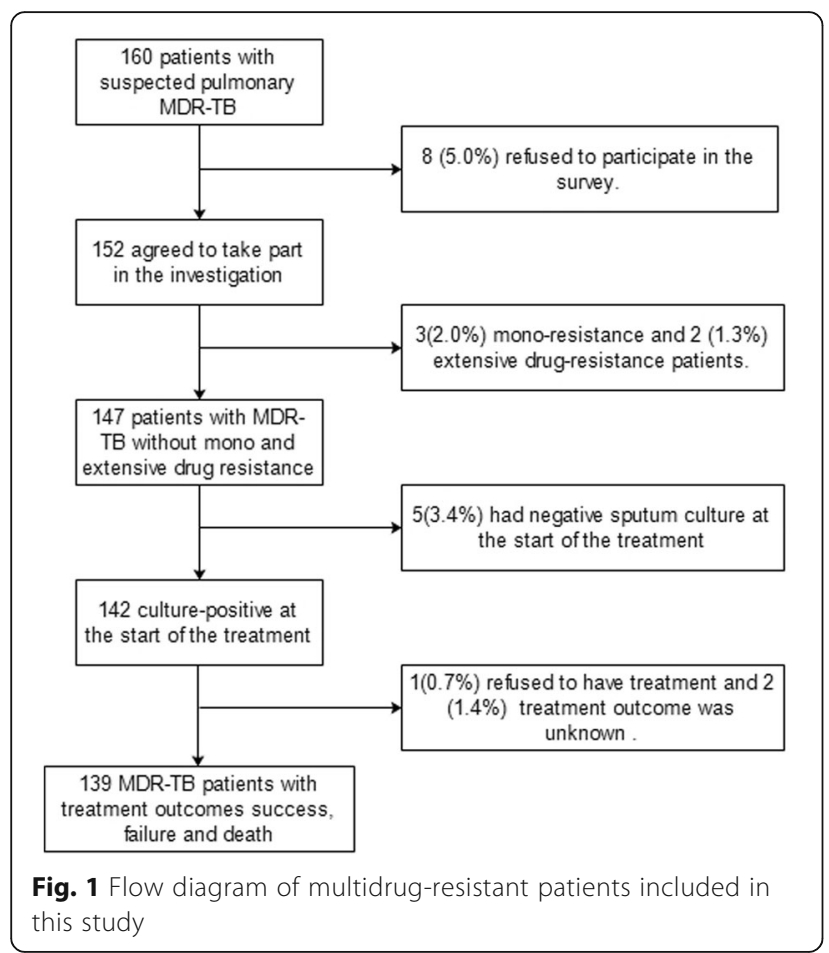

Pto); 16 (11.5\%)were treated with standard regimen 2 (SR2: 6Z Am Lfx PAS Pto/18Z Lfx PAS Pto); 3 (2.2\%) were treated with standard regimen 3 (SR3: 6Z Cm Lfx Cs Pto/18Z Lfx Cs Pto); 15 patients (10.8\%) were treated with standard regimen 4 (SR4: 6Z Cm Lfx PAS Pto/18Z Lfx Cs Pto) (Table 2).

\section{Factors contributing to sputum culture conversion}

In univariate analysis (Table 3), we found that factors associated with reduced rate of sputum culture conversion were smoking $(\mathrm{HR}=0.63 ; 95 \% \mathrm{CI}: 0.43-0.93 ; P=0.020)$, drinking $(\mathrm{HR}=0.49 ; 95 \% \mathrm{CI}: 0.27-0.89 ; P=0.019)$, Ofx resistance $(\mathrm{HR}=0.46 ; 95 \% \mathrm{CI}: 0.29-0.73 ; P=0.001)$, and a sputum smear grade $>1(\mathrm{HR}=0.61 ; 95 \% \mathrm{CI}$ : $0.41-0.91$; $P=0.001)$. No significant difference was found between the presence of lung lesions during the baseline chest radiographic examination and sputum culture conversion $(\mathrm{HR}=1.17$; 95\% CI: 0.79-1.71; $P=0.32)$.

We further performed a multivariate regression and found that smoking $(\mathrm{HR}=0.44 ; 95 \% \mathrm{CI}: 0.23-0.83 ; P=$ $0.011)$, drinking $(\mathrm{HR}=0.41 ; 95 \% \mathrm{CI}: 0.21-0.81 ; P=0.011)$, Ofx resistance $(\mathrm{HR}=0.43 ; 95 \% \mathrm{CI}: 0.24-0.76 ; P=0.003)$ and a sputum smear grade $>1(\mathrm{HR}=0.51$; $95 \% \mathrm{CI}$ : $0.31-$ $0.83 ; P=0.008)$ continued to be associated with sputum culture conversion (Table 4).

\section{Discussion}

To our knowledge, there is no similar study in China, to investigate factors that influenced sputum culture conversion in the process of treatment of MDR-TB disease.
Table 1 Demographic and clinical characteristics of 139 multidrug-resistant tuberculosis patients

\begin{tabular}{|c|c|c|}
\hline Variable & Median (IQR) & No. (\%) \\
\hline \multicolumn{3}{|l|}{ Gender } \\
\hline Male & & 99 (71.4) \\
\hline Female & & $40(28.6)$ \\
\hline Age, years & $51.0(35.8-60.0)$ & \\
\hline$\leq 51$ & & $71(51.1)$ \\
\hline$>51$ & & $68(48.9)$ \\
\hline Weight, kilograms & $60.0(53.0-65.0)$ & \\
\hline$\leq 60$ & & 79 (56.8) \\
\hline$>60$ & & $60(43.2)$ \\
\hline \multicolumn{3}{|l|}{ Occupation } \\
\hline Peasant & & $44(31.7)$ \\
\hline Worker & & $18(13.0)$ \\
\hline Unemployed & & $61(43.9)$ \\
\hline Others $^{\&}$ & & $16(11.5)$ \\
\hline \multicolumn{3}{|l|}{ Smoking } \\
\hline Yes & & $65(46.8)$ \\
\hline No & & $72(51.8)$ \\
\hline Missing & & $2(1.4)$ \\
\hline \multicolumn{3}{|l|}{ Drinking } \\
\hline Yes & & $26(18.7)$ \\
\hline No & & $86(61.9)$ \\
\hline Missing & & $27(19.4)$ \\
\hline \multicolumn{3}{|l|}{ Lung cavitation } \\
\hline Yes & & $72(51.8)$ \\
\hline No & & $62(44.6)$ \\
\hline Missing & & $3(2.2)$ \\
\hline \multicolumn{3}{|l|}{ Lung lesions } \\
\hline Yes & & $129(92.8)$ \\
\hline No & & $3(2.2)$ \\
\hline Missing & & $7(5.0)$ \\
\hline \multicolumn{3}{|c|}{ Resistant to ofloxacin } \\
\hline Yes & & $42(58.3)$ \\
\hline No & & $81(30.2)$ \\
\hline Missing & & $16(11.5)$ \\
\hline \multicolumn{3}{|c|}{ Resistant to Kanamycin } \\
\hline Yes & & $15(10.8)$ \\
\hline No & & $103(74.1)$ \\
\hline Missing & & $21(15.1)$ \\
\hline \multicolumn{3}{|c|}{ Sputum smear grade } \\
\hline$\leq 1$ & & $51(36.7)$ \\
\hline$>1$ & & $87(62.6)$ \\
\hline Missing & & $1(0.7)$ \\
\hline
\end{tabular}

Abbreviations: No. number IQR interquartile range. \& including civil servants, teachers, students etc 
Table $\mathbf{2}$ Chemotherapy regimens of the MDR-TB patients

\begin{tabular}{lll}
\hline Variable & Chemotherapy regimen & $\mathrm{N}(\%)$ \\
\hline Individualized regimen & Distinct from patient-to-patient & $63(45.3 \%)$ \\
Regimen 1 & 6 Pyrazinamide Amikacin Levofloxacin Cycloserine Protionamide & $42(30.2 \%)$ \\
& $/ 18$ Pyrazinamide Levofloxacin Cycloserine Protionamide & \\
Regimen 2 & 6 Pyrazinamide Amikacin Levofloxacin Para-amino salicylic acid Protionamide & $16(11.5 \%)$ \\
& $/ 18$ Pyrazinamide Levofloxacin Para-amino salicylic acid Protionamide & $3(2.2 \%)$ \\
Regimen 3 & 6 Pyrazinamide Capreomycin Levofloxacin Cycloserine Protionamide & /18 Pyrazinamide Levofloxacin Cycloserine Protionamide \\
Regimen 4 & 6 Pyrazinamide Capreomycin Levofloxacin Para-amino salicylic acid Protionamide & $15(10.8 \%)$ \\
\hline
\end{tabular}

Abbreviations: MDR-TB multidrug-resistant tuberculosis, $N$ number

In this setting with a high burden of drug resistant tuberculosis, we further validated that time to sputum culture conversion is a useful prognostic tool to predict end-of-treatment outcomes in MDR-TB patients but that results differ substantially depending on the month of treatment in which conversion occurs $[5,6]$. The median time of sputum smear conversion was 91.5 days, which was similar with a recent study by B. Velayutham and longer than it reported in earlier studies [14-17]. This might because during the time waiting for the DST results, clinicians usually give the anti-TB drugs according to their experience and previous medication history of the patients, which could results in the culture conversion of the patients before the initiation of the standardized treatment, who were then were excluded before the initiation of the treatments.

After multivariable analysis, we further assessed factors associated with increased delay in culture conversion. We found that resistance to Ofx, smoking, drinking, and a high sputum smear grade were risk factors affecting culture conversion. Yuen et al. suggested that MDR-TB regimens including more potentially effective drugs are likely to improve treatment response in MDR-TB patients [18]. To evaluate the association between regimen composition and treatment response, we made a comparison between individualized and standardized drug regimens and treatment outcomes. We found no statistically significant differences however this may be due to statistical power during stratification.

Substantial evidence exists indicating that smoking delays culture conversion and adversely affects end-of-treatment outcomes in drug-susceptible TB patients [19-22]. For example, Maciel et al. found that TB patients that smoked were approximately three times less likely to convert their sputum culture after two months compared to non-smoking TB patients. Leung CC et al. also found that approximately one in six treatment failures were due to patient smoking habits [20]. A recent study conducted in Brazil demonstrated that tobacco smoking delayed culture conversion during treatment for pulmonary tuberculosis and that this relationship was dose-dependent [21]. Whether smoking also delays culture conversion in MDR-TB patients has not been investigated previously and we were able to extend these previous findings in drug-susceptible TB patients [19-21] to MDR-TB patients. In this study, we found that smokers had a higher risk for persistent culture-positivity compared with nonsmokers after adjustment for potential confounders. MDR-TB patients may have ceased smoking after hospital admission and this could have led to misclassification of patient smoking status. However, this bias, if present, likely brings the association between smoking and delayed culture conversion among MDR-TB patients towards the null. Smoking cessation programs in an attempt to reduce poor treatment outcomes may be an important supplementary control measure for TB programs dealing with a high-burden of drug resistance TB, such as China.

A few studies have shown that sputum culture conversion can be delayed in patients who have infecting isolates resistant to second line anti-TB drugs [6, 22, 23]. After adjustment for confounders, we found that participants resistant to Ofx were significantly less likely to have sputum culture conversion. Fluoroquinolones are amongst the most effective medications for patients not susceptible to first line drugs and therefore play an important role in treating drug resistant tuberculosis [24, 25]. Nevertheless, excessive and irregular medication were leading causes for fluoroquinolone resistance in Pakistan [26, 27]. We found that, patients resistant to Ofx were over two times more likely to have continuous culture-positive laboratory tests by the end of multidrug-resistant TB treatment. Fluoroquinolone resistance is a potential critical threat to the control of drug resistant TB globally and efforts to prevent resistance through high medication compliance in highburden settings are essential. 
Table 3 Factors related to sputum culture conversion amongst multidrug-resistant patients in Jiangsu Province, China $(N=139)$

\begin{tabular}{|c|c|c|c|c|}
\hline Variable & N (\%) & $\mathrm{HR}$ & $95 \% \mathrm{Cl}$ & $P$-value \\
\hline \multicolumn{5}{|l|}{ Age, years } \\
\hline$\leq 51$ & $99(71.4)$ & Reference & & \\
\hline$>51$ & $40(28.6)$ & 0.77 & $0.53-1.14$ & 0.190 \\
\hline \multicolumn{5}{|l|}{ Gender } \\
\hline Male & $71(51.1)$ & Reference & & \\
\hline Female & 68 (48.9) & 0.90 & $0.59-1.36$ & 0.604 \\
\hline \multicolumn{5}{|l|}{ Weight, kilograms } \\
\hline$\leq 60$ & 79 (56.8) & Reference & & \\
\hline$>60$ & $60(43.2)$ & 0.91 & $0.62-1.33$ & 0.607 \\
\hline \multicolumn{5}{|l|}{ Smoking } \\
\hline No & $72(51.8)$ & Reference & & \\
\hline Yes & $65(46.8)$ & 0.63 & $0.43-0.93$ & 0.020 \\
\hline Missing & $2(1.4)$ & & & \\
\hline \multicolumn{5}{|l|}{ Drinking } \\
\hline No & $86(61.9)$ & Reference & & \\
\hline Yes & $26(18.7)$ & 0.49 & $0.27-0.89$ & 0.019 \\
\hline Missing & $27(19.4)$ & & & \\
\hline \multicolumn{5}{|l|}{ Ofloxacin } \\
\hline Drug sensitive & $103(74.1)$ & Reference & & \\
\hline Drug resistance & $15(10.8)$ & 0.46 & $0.29-0.73$ & 0.001 \\
\hline Missing & $21(15.1)$ & & & \\
\hline \multicolumn{5}{|l|}{ Kanamycin } \\
\hline Drug sensitive & $81(30.2)$ & Reference & & \\
\hline Drug resistance & $42(58.3)$ & 0.72 & $0.37-1.38$ & 0.320 \\
\hline Missing & $16(11.5)$ & & & \\
\hline \multicolumn{5}{|c|}{ Sputum smear grade } \\
\hline$\leq 1$ & $51(36.7)$ & Reference & & \\
\hline$>1$ & $87(62.6)$ & 0.61 & $0.41-0.91$ & 0.001 \\
\hline Missing & $1(0.7)$ & & & \\
\hline \multicolumn{5}{|l|}{ Lung lesions } \\
\hline No & $3(2.2)$ & Reference & & \\
\hline Yes & $129(92.8)$ & 1.17 & $0.79-1.71$ & 0.436 \\
\hline Missing & $7(5.0)$ & & & \\
\hline \multicolumn{5}{|l|}{ Baseline regimens } \\
\hline SR & 77 (55.4) & Reference & & \\
\hline IR & $62(44.6)$ & 1.34 & $0.76-2.37$ & 0.32 \\
\hline
\end{tabular}

Abbreviations: $H R$ hazard ratio, $\mathrm{Cl}$ confidence interval, $I R$ individualized regimens, SR standard regimen. SR: include SR1, SR2, SR3 and SR4 regiments

Rie Kanda et al. reported the time of the sputum culture conversion was prolonged by high smear grade [28], consistent with the results of F. Qazi et al. in 2011 [22] and Caetano Mota et al. in 2012 [29]. Also, patients with a high colony count were less likely to convert than those
Table 4 Multivariate analysis of predictors of sputum culture conversion among multidrug-resistant patients in Jiangsu Province, China $(N=139)$

\begin{tabular}{|c|c|c|c|}
\hline \multirow[t]{2}{*}{ Variable } & \multicolumn{3}{|c|}{ Adjusted Model* } \\
\hline & $\mathrm{HR}$ & $95 \% \mathrm{Cl}$ & $P$-value \\
\hline \multicolumn{4}{|l|}{ Age, years } \\
\hline$\leq 51$ & Reference & & \\
\hline$>51$ & 1.09 & $0.62-1.91$ & 0.766 \\
\hline \multicolumn{4}{|l|}{ Gender } \\
\hline Male & Reference & & \\
\hline Female & 0.61 & $0.34-1.11$ & 0.105 \\
\hline \multicolumn{4}{|l|}{ Smoking } \\
\hline No & Reference & & \\
\hline Yes & 0.44 & $0.23-0.83$ & 0.011 \\
\hline \multicolumn{4}{|l|}{ Drinking } \\
\hline No & Reference & & \\
\hline Yes & 0.41 & $0.21-0.81$ & 0.011 \\
\hline \multicolumn{4}{|l|}{ Ofloxacin } \\
\hline Drug sensitive & Reference & & \\
\hline Drug resistance & 0.43 & $0.24-0.76$ & 0.003 \\
\hline \multicolumn{4}{|c|}{ Sputum smear grade } \\
\hline$\leq 1$ & Reference & & \\
\hline$>1$ & 0.51 & $0.31-0.83$ & 0.008 \\
\hline
\end{tabular}

who had a low smear grade. In our study, patients with a smear grade $>+1$ had a lower likelihood of sputum smear conversion compared with those with a smear grade $\leq+1$. It might be natural that MDR-TB patients who had a higher colony count take a longer time for sputum culture conversion. This result highlights the importance of early detection and treatment of drug resistant TB patients.

There are several limitations of this study. First, all patients ceased smoking and drinking during treatment, which may have led to nondifferential misclassification driving our results toward the null. Moreover, we did not quantify smoking or drinking in more detail which may have led to a lack of an effect on culture conversion. Second, missing information was present among some of our variables of interest. To account for this, we attempted to retrieve any missing information by revisiting participants and checking the infectious disease reporting system. Third, this survey did not collect information on HIV infection status and this may potentially be an important confounder. Patients with tuberculosis in China are not routinely tested for HIV and, due to this we were unable to assess the influence of HIV coinfection. 


\section{Conclusions}

In conclusion, we present a prospective cohort study of MDR-TB patients from urban China and we found MDRTB patients that smoke, drink, have ofloxacin resistance, or a high smear grade are less likely to respond to treatment and should be meticulously followed up. A multidimensional approach is needed to effectively control TB, including early detection and treatment, and proper interventions to lower the drinking rate and cigarette smoking rate.

\begin{abstract}
Abbreviations
AFB: acid-fast bacillus; Am: amikacin; Cm: capreomycin; Cs: cycloserine; DST: traditional drug sensitivity tests; E: ethambutol; HIV: human immunodeficiency virus; HR: hazard ratio; INH: rifampicin; IR: individualized regimens; Km: kanamycin; Lfx: levofloxacin; MDR-TB: multidrug-resistant tuberculosis; Mfx: moxifloxacin; MTB: Mycobacterium tuberculosis; Ofx: ofloxacin; PAS: para-amino salicylic acid; Pto: protionamide; RMP: isoniazid; SR: standard regimen; TB: tuberculosis; Z: pyrazinamide
\end{abstract}

\section{Acknowledgements}

Not applicable.

\section{Funding}

This study was supported by the National Science and Technology Major Project (2018ZX10103002-001-006), National Science and Technology Major Project (2018ZX10103002-003-003).

\section{Availability of data and materials}

The datasets generated and analyzed during the current study are not publicly available due to some of datasets derived from tuberculosis patients management information system, which is confidential in China.

\section{Authors' contributions}

$\mathrm{QL}, \mathrm{PL}, \mathrm{LZ}$ conceived the study, analyzed the data and drafted the manuscript; WL, HY, XD participated in the study design, implemented the field investigation; LM participated in the study design and helped draft the manuscript. All authors contributed to the study and have read and approved the final manuscript.

\section{Ethics approval and consent to participate}

This study was reviewed and approved by the Ethics Committee of Jiangsu Province Centre for Disease Control and Prevention. The study was conducted in accordance with approved guidelines, and written informed consent was obtained from all eligible TB patients.

\section{Consent for publication}

Not applicable.

\section{Competing interests}

The authors declare that they have no competing interests.

\section{Publisher's Note}

Springer Nature remains neutral with regard to jurisdictional claims in published maps and institutional affiliations.

\footnotetext{
Author details

${ }^{1}$ Department of Chronic Communicable Disease, Center for Disease Control and Prevention of Jiangsu Province, Nanjing, Jiangsu Province, People's Republic of China. ${ }^{2}$ Department of Epidemiology and Biostatistics, School of Public Health, Nanjing Medical University, Nanjing, People's Republic of China. ${ }^{3}$ Department of Epidemiology and Biostatistics, University of Georgia School of Public Health, Athens, Georgia. ${ }^{4}$ Institute of Parasitic Disease of Jiangsu Province, Wuxi, Jiangsu Province, People's Republic of China.
}

Received: 1 April 2017 Accepted: 28 February 2018

Published online: 06 March 2018

\section{References}

1. World Health Organization. Global tuberculosis report 2015; http://www. who.int/tb/publications/global_report/en/.

2. Teixeira L, Perkins MD, Johnson JL, Keller R, Palaci M, do Valle Dettoni V Canedo Rocha LM, Debanne S, Talbot E, Dietze R. Infection and disease among household contacts of patients with multidrug-resistant tuberculosis. Int J Tuberc Lung Dis. 2001;5(4):321-8.

3. Nagaraja C, Shashibhushan BL, Asif M, Manjunath PH, Sagar C. Pattern of drug-resistance and treatment outcome in multidrug-resistant pulmonary tuberculosis. Indian J Chest Dis Allied Sci. 2012;54(1):23-6.

4. Kurbatova EV, Gammino VM, Bayona J, Becerra MC, Danilovitz M, Falzon D, Gelmanova I, Keshavjee S, Leimane V, Mitnick CD. Predictors of sputum culture conversion among patients treated for multidrug-resistant tuberculosis. Int J Tuberc Lung Dis. 2012;16(10):1335-43.

5. Kurbatova EV, Cegielski JP, Lienhardt C, Akksilp R, Bayona J, Becerra MC, Caoili J, Contreras C, Dalton T, Danilovits M. Sputum culture conversion as a prognostic marker for end-of-treatment outcome in patients with multidrug-resistant tuberculosis: a secondary analysis of data from two observational cohort studies. Lancet Respir Med. 2015;3(3):201-9.

6. Basit A, Ahmad N, Khan AH, Javaid A, Syed Sulaiman SA, Afridi AK, Adnan AS, Haq I, Shah SS, Ahadi A, et al. Predictors of two months culture conversion in multidrug-resistant tuberculosis: findings from a retrospective cohort study. PLoS One. 2014;9(4):e93206.

7. Singla R, Sarin R, Khalid UK, Mathuria K, Singla N, Jaiswal A, Puri MM, Visalakshi P, Behera D. Seven-year DOTS-plus pilot experience in India: results, constraints and issues. Int J Tuberc Lung Dis. 2009;13(8):976-81.

8. Rodriguez M, Monedero I, Caminero JA, Encarnacion M, Dominguez $Y$, Acosta I, Munoz E, Camilo E, Martinez-Selmo S, de los Santos S, et al. Successful management of multidrug-resistant tuberculosis under programme conditions in the Dominican Republic. Int J Tuberc Lung Dis. 2013;17(4):520-5.

9. Zhao Y, Xu S, Wang L, Chin DP, Wang S, Jiang G, Xia H, Zhou Y, Li Q, Ou X. National survey of drug-resistant tuberculosis in China. N Engl J Med. 2012;366(23):2161-70.

10. Gandhi NR, Nunn P, Dheda K, Schaaf HS, Zignol M, Van Soolingen D, Jensen $P$, Bayona J. Multidrug-resistant and extensively drug-resistant tuberculosis: a threat to global control of tuberculosis. Lancet. 2010;375(9728):1830-43.

11. Peng L, Qiao L, Martinez L, Yang H, Wei L, Ding X, Zhu L. Time to sputum culture conversion and treatment outcome of patients with multidrugresistant tuberculosis: a prospective cohort study from urban China. Eur Respir J. 2017;49(3):1601558.

12. Liu Q, Zhu L, Shao Y, Song H, Li G, Zhou Y, Shi J, Zhong C, Chen C, Lu W. Rates and risk factors for drug resistance tuberculosis in northeastern China. BMC Public Health. 2013;13(1):1.

13. Jaramillo E. Guidelines for the programmatic management of drug-resistant tuberculosis. Geneva: World Health Organization; 2008.

14. Velayutham B, Nair D, Kannan T, Padmapriyadarsini C, Sachdeva KS, Bency J, Klinto JS, Haldar S, Khanna A, Jayasankar S, et al. Factors associated with sputum culture conversion in multidrug-resistant pulmonary tuberculosis. Int J Tuberc Lung Dis. 2016;vol 20:1671-6.

15. Holtz TH, Sternberg M, Kammerer S, Laserson KF, Riekstina V, Zarovska E, Skripconoka $V$, Wells CD, Leimane V. Time to sputum culture conversion in multidrug-resistant tuberculosis: predictors and relationship to treatment outcome. Ann Intern Med. 2006;144(9):650-9.

16. Magee MJ, Kempker RR, Kipiani M, Tukvadze N, Howards PP, Narayan KM, Blumberg HM. Diabetes mellitus, smoking status, and rate of sputum culture conversion in patients with multidrug-resistant tuberculosis: a cohort study from the country of Georgia. PLoS One. 2014;9(4):e94890.

17. Hafkin J, Modongo C, Newcomb C, Lowenthal E, Macgregor RR, Steenhoff $A P$, Friedman H, Bisson GP. Impact of the human immunodeficiency virus on early multidrug-resistant tuberculosis treatment outcomes in Botswana. Int J Tuberc Lung Dis. 2013;17(3):348-53.

18. Yuen CM, Kurbatova EV, Tupasi T, Caoili JC, Van Der Walt M, Kvasnovsky C, Yagui M, Bayona J, Contreras C, Leimane V, et al. Association between regimen composition and treatment response in patients with multidrug-resistant tuberculosis: a prospective cohort study. PLoS Med. 2015;12(12):e1001932.

19. Maciel EL, Brioschi AP, Peres RL, Guidoni LM, Ribeiro FK, Hadad DJ, Vinhas SA, Zandonade E, Palaci M, Dietze R, et al. Smoking and 2-month culture 
conversion during anti-tuberculosis treatment. Int J Tuberc Lung Dis. 2013;17(2):225-8.

20. Leung CC, Yew WW, Chan CK, Chang KC, Law WS, Lee SN, Tai LB, Leung EC, Au RK, Huang SS, et al. Smoking adversely affects treatment response, outcome and relapse in tuberculosis. Eur Respir J. 2015;45(3):738-45.

21. Nijenbandring de Boer R, Souza Filho JB O e, Cobelens F, Ramalho Dde P, Campino Miranda PF, Logo K, Oliveira H, Mesquita E, Oliveira MM, Kritski A. Delayed culture conversion due to cigarette smoking in active pulmonary tuberculosis patients. Tuberculosis (Edinb). 2014;94(1):87-91.

22. Qazi F, Khan U, Khowaja S, Javaid M, Ahmed A, Salahuddin N, Hussain H, Becerra MC, Golub JE, Khan AJ. Predictors of delayed culture conversion in patients treated for multidrug-resistant tuberculosis in Pakistan. Int J Tuberc Lung Dis. 2011;15(11):1556.

23. Mitnick CD, Shin SS, Seung KJ, Rich ML, Atwood SS, Furin JJ, Fitzmaurice GM, Alcantara Viru FA, Appleton SC, Bayona JN, et al. Comprehensive treatment of extensively drug-resistant tuberculosis. N Engl J Med. 2008;359(6):563-74.

24. Caminero JA, Sotgiu G, Zumla A, Migliori GB. Best drug treatment for multidrug-resistant and extensively drug-resistant tuberculosis. Lancet Infect Dis. 2010;10(9):621-9.

25. Chan ED, Laurel V, Strand MJ, Chan JF, Huynh M-LN, Goble M, Iseman MD. Treatment and outcome analysis of 205 patients with multidrug-resistant tuberculosis. Am J Respir Crit Care Med. 2004;169(10):1103-9.

26. Jabeen K, Shakoor S, Chishti S, Ayaz A, Hasan R. Fluoroquinolone-resistant mycobacterium tuberculosis, Pakistan, 2005-2009. Emerg Infect Dis. 2011:17(3):564-6.

27. Wells WA, Ge CF, Patel N, Oh T, Gardiner E, Kimerling ME. Size and usage patterns of private TB drug markets in the high burden countries. PLoS One. 2011;6(5):e18964

28. Kanda R, Nagao T, Tho NV, Ogawa E, Murakami Y, Osawa M, Saika Y, Doi K, Nakano Y. Factors affecting time to sputum culture conversion in adults with pulmonary tuberculosis: a historical cohort study without censored cases. PLoS One. 2015:10(11):e0142607.

29. Caetano Mota P, Carvalho A, Valente I, Braga R, Duarte R. Predictors of delayed sputum smear and culture conversion among a Portuguese population with pulmonary tuberculosis. Rev Port Pneumol. 2012;18(2):72-9.

\section{Submit your next manuscript to BioMed Central and we will help you at every step:}

- We accept pre-submission inquiries

- Our selector tool helps you to find the most relevant journal

- We provide round the clock customer support

- Convenient online submission

- Thorough peer review

- Inclusion in PubMed and all major indexing services

- Maximum visibility for your research

Submit your manuscript at www.biomedcentral.com/submit

) Biomed Central 